\title{
GAMBARAN SKALA NYERI PADA PASIEN PASCABEDAH CAESAR DENGAN PENGGUNAAN OBAT KETAMIN DOSIS RENDAH
}

\author{
${ }^{1}$ Richi M. Posumah \\ ${ }^{2}$ Harold F. Tambajong \\ ${ }^{2}$ Lucky T. Kumaat \\ ${ }^{1}$ Kandidat Skripsi Fakultas Kedokteran Universitas Sam Ratulangi \\ ${ }^{2}$ Bagian Anestesiologi dan Terapi Intensif Fakultas Kedokteran Universitas Sam Ratulangi \\ Manado \\ Email : richimposumah@gmail.com
}

\begin{abstract}
Pain is an uncomfortable sensorical feeling and emotional experience that relate to the destruction of tissue actually or potentially. Pain management is an important thing for the postoperative patients. Postoperative pain causing the change of body hormones that eventually lead to pain, nausea and vomitting. Postoperative pain management is an important aspect and therefore the analgetic drugs will be administered to overcome the pain. Not only function as an anaesthetic agent, low dose ketamine also has an analgetic effect. This study was aimed to determine the pain scale of the caesarean section patients using low - dose ketamine. This is an descriptive prospective study and the samples were the postoperative caesarean section patients from Prof. DR. R.D Kandou Hospital, Bhayangkara Hospital and GMIM Pancaran Kasih Hospital in Manado from December 2015 January 2016. Patient that has been finished the operation were administered low dose ketamine as bolus $0,1 \mathrm{mg} / \mathrm{kg}$ and continuous IV $0,1 \mathrm{mg} / \mathrm{kg} /$ hour for 6 hours then the pain were assessed by using the Numerical Rating Scale (NRS) and FACES Pain Scale (FPS) starts from two hours, four hours and six hours after the ketamine was administered. Conclusion : Low dose ketamine was able to lower postoperative pain on caesarean section patients.
\end{abstract}

Keywords : Postoperative Pain, Pain Scale, Caesarean Section, Low - Dose Ketamine

\begin{abstract}
Abstrak : Nyeri merupakan perasaan sensorik dan pengalaman emosional yang tidak nyaman dan berhubungan dengan kerusakan jaringan secara actual maupun potensial. Manajemen nyeri merupakan hal yang penting dalam penganganan pasien pascabedah. Nyeri yang disebabkan oleh pembedahan terjadi karena perubahan hormon - hormon dalam tubuh dan hasilnya berupa rasa nyeri, mual dan muntah. Manajemen nyeri pascabedah merupakan aspek penting maka diberikan obat analgetik untuk mengatasinya. Selain sebagai obat anestetik, obat ketamin dengan dosis rendah memiliki fungsi analgetik. Tujuan penelitian ini adalah untuk mengetahui gambaran skala nyeri pada pasien pascabedah caesar dengan menggunakan obat ketamin dosis rendah. Penelitian ini bersifat deskriptif prospektif dan sampel merupakan pasien pascabedah caesar diambil di RSUP. Prof. DR. R. D. Kandou Manado, RS Bhayangkara Mando dan RSU GMIM Pancaran Kasih Manado yang dilaksanakan pada bulan Desember 2015 - Januari 2016. Pasien setelah selesai operasi diberikan ketamin dosis rendah dengan dosis bolus $0,1 \mathrm{mg} / \mathrm{kg}$ dan infus kontinyu IV $0,1 \mathrm{mg} / \mathrm{kg} / \mathrm{jam}$ selama 6 jam kemudian penilaian nyeri pasien menggunakan skala nyeri Numerical Rating Scale (NRS) dan FACES Pain Scale (FPS) pada jam II, jam IV dan jam VI setelah pemberian obat ketamin. Simpulan : Ketamin dengan dosis rendah mampu menurunkan nyeri pascabedah pada pasien bedah caesar.
\end{abstract}

Kata Kunci : Nyeri Pascabedah, Skala Nyeri, Bedah Caesar, Ketamin Dosis Rendah 
Sejalan dengan berkembangnya pembedahan dan anestesi, tenaga anestesi membutuhkan beberapa keahlian baru, termasuk keahlian dalam resusitasi, penggantian cairan, manajemen jalan napas, transport oksigen, reduksi stress akibat operasi, dan manajemen nyeri pascabedah. ${ }^{1}$ Seorang dokter tidak selalu mampu menyembuhkan penyakit tetapi selalu berusaha untuk mengurangi penderitaan. Para ahli anestesi dapat melakukan manajemen nyeri yang diakibatkan oleh pembedahan dan penggunaan obat analgetik merupakan hal yang penting dari komponen anestesi. Ahli anestesi lebih mampu menggunakan opiad dibandingkan profesi lainnya karena kemampuan farmakologi yang dimiliki. Bertambahnya jumlah ahli anestesi dalam tindakan manajemen nyeri serta kemampuan yang efektif dalam pemulihan pasien tetap menjadi komponen penting dari tugas seorang ahli anestesi. ${ }^{2}$ Survei yang dilakukan di rumah sakit menunjukkan bahwa sebagian besar pasien mengalami nyeri sedang hingga berat (Tabel 1). Survei yang lain juga menunjukkan hal yang sama dimana hingga 72 jam setelah pembedahan menunjukkan bahwa nyeri sedang dan berat adalah hal yang umum terjadi. $^{3}$

Tabel 1. Nyeri di rumah sakit berdasarkan survei pada 36 Rumah Sakit

\begin{tabular}{ccc}
\hline Masalah & Jumlah/Total & Persentase \\
\hline $\begin{array}{c}\text { Nyeri muncul } \\
\text { setiap saat }\end{array}$ & $1042 / 3162$ & 33 \\
$\begin{array}{c}\text { Nyeri sedang } \\
\text { hingga berat } \\
\text { Nyeri berat } \\
\text { saja }\end{array}$ & $2755 / 3157$ & 87 \\
Pasien & $182 / 1051$ & 17 \\
meminta & $1085 / 2589$ & 42 \\
diberikan obat \\
$\begin{array}{c}\text { Obat tidak } \\
\text { diberikan } \\
\text { pada }\end{array}$ & $455 / 1085$ & 41 \\
waktunya & & \\
\hline
\end{tabular}

Bedah caesar bertambah penggunaannya di negara berkembang dan negara maju. Betran dkk (2007) menghitung proporsi penggunaan bedah caesar pada tingkat regional maupun global. Data tersedia dari 126 negara, dengan 89\% pasien berhasil menjalani bedah caesar. Angka penggunaan bedah caesar pada skala global sekitar 15\%. Angka lebih besar terdapat pada negara maju, dan lebih rendah di negara berkembang. ${ }^{4}$ (Tabel 2)

Tabel 2. Laju perkembangan penggunaan bedah caesar pada berbagai negara. (Betran et. Al. 2007)

\begin{tabular}{cc}
\hline Region & $\begin{array}{c}\text { Kelahiran } \\
\text { melalui Bedah } \\
\text { Caesar (\%) }\end{array}$ \\
\hline Afrika & 3.5 \\
Asia & 15.9 \\
Eropa & 19.0 \\
Amerika Latin dan & 29.2 \\
Karibia & \\
Australia/ New Zealand & 21.6 \\
Total Global & 15.0 \\
Negara Maju & 21.1 \\
Negara Berkembang & 14.3 \\
\hline
\end{tabular}

Manajemen nyeri akut pascabedah merupakan aspek penting pada perawatan anestesi. Ketamin merupakan salah satu obat pilihan dalam manajemen nyeri. Pada total 70 penelitan terdapat 4701 pasien (2049 pasien pada grup placebo dan 2652 pasien pada grup ketamin). Secara keseluruhan, 37,5\% hasil penelitian pada grup ketamin menunjukkan penurunan nyeri yang signifikan pada jam awal (30 menit-4 jam), dan 25\% menunjukkan penurunan nyeri signifikan pada jam terakhir (24-72 jam). Pada grup dengan penggunaan placebo, $78 \%$ pasien merasakan peningkatan nyeri yang signifikan dibandingkan grup yang menggunakan ketamin. Hanya sekitar 16\% pasien yang tidak merasakan perubahan berarti dari ketamin. ${ }^{5}$ Berdasarkan penjelasan diatas, maka kami ingin mengetahui gambaran 
skala nyeri pada pasien pascabedah caesar dengan menggunakan obat ketamin dosis rendah.

\section{METODE PENELITIAN}

Penelitian ini bersifat deskriptif prospektif dilakukan di RSUP Prof. DR. R. D. Kandou Manado, RS Bhayangkara Manado, RSU. GMIM Pancaran Kasih Manado mulai bulan Desember 2015 sampai Januari 2016. Pengambilan sampel diambil dengan metode konsekutif sampling. Kriteria inklusi yaitu pasien yang akan menjalani bedah caesar, pasien umur 18-50 Tahun, pasien dengan kriteria ASA I dan ASA II, obat analgetik ketamin dosis rendah dengan bolus $0,1 \mathrm{mg} / \mathrm{kg}$ IV dan infus IV sebesar $0,1 \mathrm{mg} / \mathrm{kg} / \mathrm{jam}$, teknik anestesi spinal dengan obat bupivakain 0,5\% (Hiperbarik). Kriteria eksklusi yaitu pasien yang menolak ikut serta dalam penelitian, pasien dengan kontraindikasi pembedahan, lama pembedahan diatas 2 jam, riwayat halusinasi, riwayat penyalahgunaan obat dan nyeri kronik. Pengambilan sampel penelitian dilakukan dengan menggunakan metode purposive sampling dimana kelompok populasi dipilih berdasarkan kemauan peneliti bahwa individu tersebut adalah sesuai untuk dijadikan sampel. Pasien yang selesai dioperasi diberikan obat ketamin dan nyeri dinilai dengan skala nyeri Numerical Rating Scale (NRS) dan FACES Pain Scale (FPS) pada jam II, jam IV dan jam VI setelah diberikan obat ketamin.

\section{Hasil Penelitian}

Diperoleh 12 pasien bedah caesar dengan anestesi blok subaraknoid (spinal) menggunakan obat anestetik bupivakain dan setelah pembedahan pasien diberikan obat analgetik ketamin dosis rendah. Pasien dengan kelompok umur 21 - 30 Tahun sebanyak 6 orang (50\%), kelompok umur 31 - 40 Tahun sebanyak 5 orang $(41,6 \%)$ dan kelompok umur 41 - 50 Tahun sebanyak 1 orang (8,3\%). (Tabel 4)

Tabel 4. Distribusi pasien menurut Umur (Sumber : Data Primer)

\begin{tabular}{cc}
\hline $\begin{array}{c}\text { Kelompok Umur } \\
\text { (Tahun) }\end{array}$ & Banyaknya Pasien \\
\hline $21-30$ & $6(50 \%)$ \\
$31-40$ & $5(41,6 \%)$ \\
$41-50$ & $1(8,3 \%)$ \\
\hline
\end{tabular}

Pasien dengan kelompok Berat Badan 51 - $60 \mathrm{Kg}$ sebanyak 2 orang (16,6\%), kelompok Berat Badan 61 - $70 \mathrm{Kg}$ sebanyak 7 orang $(58,3 \%)$ dan kelompok Berat Badan 81 - $90 \mathrm{Kg}$ sebanyak 3 orang (25\%). (Tabel 5)

Tabel 5. Distribusi pasien menurut Berat Badan (Sumber : Data Primer)

\begin{tabular}{cc}
\hline $\begin{array}{l}\text { Berat Badan } \\
\text { Pasien }(\mathrm{Kg})\end{array}$ & Banyaknya Pasien \\
\hline $51-60 \mathrm{Kg}$ & 2 Orang $(16,6 \%)$ \\
$61-70 \mathrm{Kg}$ & 7 Orang $(58,3 \%)$ \\
$71-80 \mathrm{Kg}$ & - \\
$81-90 \mathrm{Kg}$ & 3 Orang $(25 \%)$ \\
\hline
\end{tabular}

Didapatkan pasien dengan nilai NRS yang bervariasi. Pada jam II, jam IV dan jam VI didapatkan nyeri berat dan nyeri sedang. (Tabel 6)

Tabel 6. Distribusi Skala Nyeri Numerical Rating Scale (NRS) (Sumber : Data Primer)

\begin{tabular}{|c|c|c|c|}
\hline & Jam II & Jam IV & Jam VI \\
\hline NRS & 2 pasien & - & - \\
\hline $\begin{array}{c}\text { NRS } \\
9\end{array}$ & $\begin{array}{c}3 \text { pasien } \\
(25 \%)\end{array}$ & $\begin{array}{l}1 \text { pasien } \\
(8,3 \%)\end{array}$ & - \\
\hline NRS & 1 pasien & 5 pasien & 1 pasien \\
\hline 8 & $(8,3 \%)$ & (41,6 \%) & $(8,3 \%)$ \\
\hline NRS & 3 pasien & 1 pasien & 5 pasien \\
\hline 7 & (25 \%) & $(8,3 \%)$ & $(41,6 \%)$ \\
\hline NRS & 4 pasien & 4 pasien & 2 pasien \\
\hline 6 & $(33,3 \%)$ & $(33,3 \%)$ & $(16,6 \%)$ \\
\hline $\begin{array}{c}\text { NRS } \\
5\end{array}$ & - & $\begin{array}{l}1 \text { pasien } \\
(8,3 \%)\end{array}$ & $\begin{array}{c}3 \text { pasien } \\
(25 \%)\end{array}$ \\
\hline $\begin{array}{c}\text { NRS } \\
4\end{array}$ & $\begin{array}{c}1 \text { pasien } \\
(8,3 \%)\end{array}$ & - & $\begin{array}{l}1 \text { pasien } \\
(8,3 \%)\end{array}$ \\
\hline
\end{tabular}


Adapun nilai rata - rata dari skala NRS pada jam II adalah NRS 7,6; pada jam IV adalah NRS 7; dan pada jam VI adalah NRS 6,1. (Gambar 7)

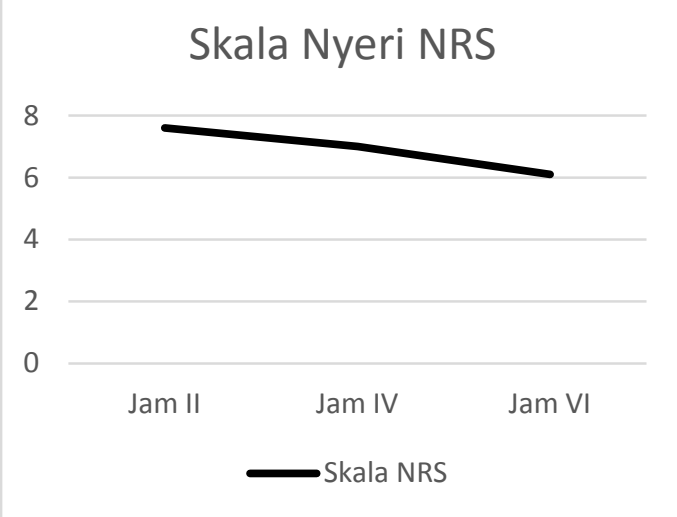

Gambar 7. Nilai rata - rata Skala NRS (Sumber : Data Primer)

Pada 12 pasien didapatkan variasi nilai skala nyeri NRS berdasarkan umur. Nilai skala didapatkan yaitu NRS 6- 7 pada umur 21 - 30 tahun, NRS 7 pada umur 31 - 40 tahun dan NRS 8 paa umur 41 50 tahun. (Tabel 7)

Tabel 7. Distribusi Skala Nyeri NRS berdasarkan Umur Pasien (Sumber : Data Primer)

\begin{tabular}{cccc}
\hline & Umur & Umur & Umur \\
& $21-30$ & $31-40$ & $41-50$ \\
\hline NRS 10 & 1 & 1 & - \\
& Pasien & Pasien & \\
NRS 9 & 1 & 2 & - \\
& Pasien & Pasien & \\
NRS 8 & 3 & 3 & 2 \\
& Pasien & Pasien & Pasien \\
NRS 7 & 4 & 4 & 1 \\
& Pasien & Pasien & Pasien \\
NRS 6 & 4 & 2 & - \\
& Pasien & Pasien & \\
NRS 5 & 3 & 1 & - \\
& Pasien & Pasien & \\
NRS 4 & 1 & - & 1 \\
& Pasien & & Pasien \\
\hline
\end{tabular}

Berdasarkan penelitian, diperoleh bahwa dari 12 sampel didapatkan pasien dengan Nilai FPS yang konstan. Pada jam II, jam IV, jam VI didapatkan perubahan nyeri sedang dan nyeri ringan. (Tabel 8)
Tabel 8. Distribusi Skala Nyeri FACES Pain Scale (FPS) (Sumber : Data Primer)

\begin{tabular}{cccc}
\hline & Jam II & Jam IV & Jam VI \\
\hline FPS 6 & 6 pasien & 8 pasien & - \\
& $(50 \%)$ & $(66,6 \%)$ & \\
FPS 4 & 6 pasien & 4 pasien & 6 pasien \\
& $(50 \%)$ & $(33,3 \%)$ & $(50 \%)$ \\
FPS 2 & - & - & 6 pasien \\
& & & $(50 \%)$ \\
\hline
\end{tabular}

Adapun nilai rerata dari Skala FPS pada jam II adalah FPS 5; pada jam IV adalah FPS 3,3; dan pada jam VI adalah FPS 3. (Gambar 8)

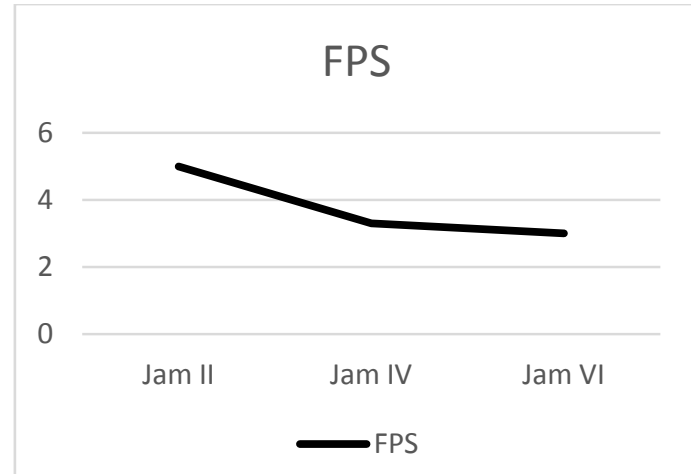

Gambar 8. Nilai rata - rata Skala FPS (Sumber : Data Primer)

Nilai FPS konstan berdasarkan 3 kelompok umur yang ada. Nilai FPS yang terbanyak dirasakan yaitu nilai FPS 4 pada 21 - 50 tahun. (Tabel 9)

Tabel 9. Distribusi Skala Nyeri FPS berdasarkan umur pasien (Sumber : Data Primer)

\begin{tabular}{cccc}
\hline & Umur & Umur & Umur \\
& $21-30$ & $31-40$ & $41-50$ \\
\hline FPS 6 & 3 & 3 & - \\
& Pasien & Pasien & \\
FPS 4 & 6 & 5 & 1 \\
& Pasien & Pasien & Pasien \\
FPS 2 & 4 & 2 & - \\
& Pasien & Pasien & \\
\hline
\end{tabular}

\section{PEMBAHASAN}

Semua pasien diberikan dosis sesuai berat badan dan menunjukkan terjadinya perubahan nyeri yang berarti. Didapatkan yaitu dosis bolus sebesar 9 mg pada seorang pasien dengan berat 
badan $90 \mathrm{~kg}$ memberikan efek pusing dan halusinasi pada jam pertama. Efek seperti ini tidak terjadi pada 11 pasien lainnya dengan berat badan dibawah 90 kg. Nilai NRS merupakan penilaian nyeri subjektif yang berarti setiap individu bervariasi dalam memberikan nilai. Nilai NRS dari semua pasien berbeda - beda dan pada kelompok umur 21 - 30 tahun skala NRS lebih rendah dibandingkan kedua kelompok umur lainnya dengan kelompok umur 31 - 40 tahun nilai NRS sedikit lebih tinggi dan nilai NRS paling tinggi terdapat pada pasien dengan umur 41 - 50 tahun. Adapun pada 1 orang pasien dengan nyeri NRS 8 pada jam II berubah menjadi NRS 4 pada jam IV dan NRS 3 pada jam VI ketika diberikan analgetik lain dalam hal ini obat parasetamol menunjukkan bahwa ketamin dikombinasikan dengan analgetik lain menurunkan nyeri secara signifikan. Nilai rata - rata dari skala NRS menunjukkan perubahan nyeri berat menjadi nyeri sedang. Selain itu idapatkan nilai FPS yang konstan dan semua pasien mengalami penurunan nilai FPS. Penilaian dengan skala FPS merupakan penilaian objektif dimana penilaian ini valid dan tidak individualistis. Distribusi skala nyeri FPS pada pasien menurut umur didapatkan bahwa umur 21 - 50 tahun memberikan nilai FPS 4. Nilai rata rata dari skala dari FPS menunjukkan perubahan nyeri mulai dari nyeri sedang $(6-4)$ menjadi nyeri ringan $(3-0)$. Beberapa penelitian telah dilakukan dengan menggunakan obat ketamin sebagai analgesik pascabedah dengan dosis rendah. Penelitian menurut Rahmanian M. et al. tentang efek dari ketamin dosis rendah kepada pasien pascabedah caesar dengan anestesi blok subaraknoid (spinal) dilakukan pada 160 pasien dan dibagi menjadi 2 kelompok. Lima menit setelah dioperasi kelompok eksperimen diberikan ketamin dosis 0,25 $\mathrm{mg} / \mathrm{kg}$ dan kelompok kontrol diberikan normal saline dengan dosis yang sama. Hasil yang didapatkan pada kelompok eksperimen yaitu nyeri yang dirasakan berkurang dan penambahan penggunaan obat analgetik lain menjadi berkurang dibandingkan dengan kelompok kontrol. ${ }^{7}$ Penelitian lain yang dilakukan oleh Sen S. et al. dengan membandingkan efek analgetik obat fentanyl dan ketamin. Sembilan puluh pasien caesar dibagi menjadi 3 kelompok dimana kelompok ketamin diberi dosis 0,15 mg/kg, kelompok kontrol diberi normal saline seperti dosis ketamin dan kelompok fentanyl diberikan dosis 10 mikrogram yang dicampur pada bupivakain saat blok subaraknoid (spinal). Ketamin dan normal saline diberikan saat anestesi spinal dimulai. Tekanan darah, curah jantung dan skala nyeri pasien diukur pada jam 24 dan 48 setelah pemberian obat analgetik. Intensitas nyeri yang dirasakan lebih rendah pada kelompok ketamin dibandingkan kedua kelompok sisanya namun setelah 24 jam nyeri yang dirasakan hampir sama pada ketiga kelompok. ${ }^{8}$ Penelitian menurut Menkiti ID et al. kepada 60 pasien caesar mengenai efek analgesia dari ketamin dosis rendah memberikan bolus ketamin sebesar $0,15 \mathrm{mg} / \mathrm{kg}$. Nyeri yang dirasakan dipantau dengan skala nyeri sampai dengan 48 jam. Didapatkan terjadi penurunan nyeri pascabedah yang signifikan. $^{9}$

\section{SIMPULAN}

Terjadi penurunan pada skala NRS dari nyeri berat menjadi nyeri sedang. Nilai rata - rata NRS pada jam II adalah NRS 7,6; pada jam IV adalah NRS 7; dan pada jam VI adalah NRS 6,1. Hasil pengamatan dengan menggunakan skala nyeri FPS yaitu terjadi penurunan dari nyeri sedang menjadi nyeri ringan. Nilai rata - rata FPS pada jam II adalah FPS 5; pada jam IV adalah FPS 3,3; dan pada jam VI adalah FPS 3. Selain itu ketamin dengan dosis rendah mampu 
menurunkan nyeri pascabedah dalam hal ini bedah caesar dan ketamin yang dikombinasikan dengan obat analgesik lain dapat menurunkan nyeri lebih signifikan.

\section{SARAN}

Disarankan bagi peneliti selanjutnya untuk membandingkan penggunaan obat ketamin dosis rendah dengan obat analgetik lainnya untuk mengetahui kemampuan analgetik ketamin dalam penurunan nyeri yang lebih signifikan. Disarankan bagi peneliti selanjutnya selain menggunakan penilaian skala nyeri yang subjektif dan objektif perlu juga dinilai parameter lain seperti profil hemodinamika pasien. Diperlukan penelitian yang lebih lanjut dan lebih mendalam mengenai penggunaan obat ketamin dosis rendah agar nantinya dapat berguna dalam tindakan medis.

\section{UCAPAN TERIMA KASIH}

Ucapan terimakasih disampaikan kepada Dr. dr. Hermanus J. Lalenoh, Sp.An, KMN, KAO, Dr. dr. Antje A. Wuwungan, Sp.An, dr. Diana Lalenoh, M.Kes, Sp.An, KNA, KAO dan pada semua pihak yang baik secara langsung maupun tidak langsung telah menumbuhkan ide atau gagasan dalam pemikiran penulis sehingga dapat menyelesaikan artikel ini.

\section{DAFTAR PUSTAKA}

\section{(1) Longernecker DE, Brown DL, Newman MF, Zapol WM. ANESTHESIOLOGY $\left(1^{\text {st }}\right.$ ed.). United States : McGraw-Hill Companies. 2008; 3; 14; 1486}
(2) Miller RD. Miller's Anesthesia $\quad\left(6^{\text {th }} \quad\right.$ ed.). Philadelphia : ELSEVIER. 2005; 3

(3) International Collaboration on Evidence-based Critical Care, Anaesthesia and Pain (ICECAP). Acute Pain. Bandolier Internet. [homepage on the Internet]. c2003 [updated 2003 February ; cited October 2015]. Available from : www.medicine.ox.ac.uk/band olier/Extraforbando/Apain.pdf

(4) Naji O, Abdallah Y, Paterson-Brown S. Cesarean Birth : Surgical Techniques. Glob. Libr. Women's med [serial online]. 2010 [cited October 2015]. Available from

www.glowm.com/section_vie w/heading/cesarean\%2520Birt h\%3A\%2520Surgical\%2520T echniques/item/133

(5) Laskowski K, Stirling A, Mckay WP, Lim HJ. A systematic review of intravenous ketamine for postoperative analgesia. Canadian Journal of Anaesthesia [serial on the Internet]. 2011 [cited October 2015]; 911-23 Available from :

www.link.springer.com/article /10.1007/s12630-011-9560$\underline{\text { 0/fulltext.html }}$

(6) Rahmanian M, Leysi M, Mirmohammadkhani M. The Effect of Low - Dose Intravenous Ketamine on Postoperative Pain Following Cesarean Section with Spinal Anesthesia : A Randomized Trial. Oman Med Journal [serial online]. January 2015 
[cited January 2016]. Avaiable from

www.ncbi.nlm.nih.gov/pmc/ar ticles/PMC4371456/\#_ffn_se ctitle

(7) Sen S, Ozmert G, Aydin O. N, Baran N, Caliskan E. The persisting analgesic effect of low - dose intravenous ketamine after spinal anaesthesia for caesarean section. PubMed [serial online]. July 2005 [cited January 2016]. Available from :

www.ncbi.nlm.nih.gov/pubme $\underline{\mathrm{d} / 16045141}$

(8) Menkiti ID, Desalu I, Kushimo OT. Low-dose intravenous ketamine improves postoperative analgesia after caesarean delivery with spinal bupivacaine in African parturients. PubMed. [serial online] July 2012 [cited January 2016]. Available from :

www.ncbi.nlm.nih.gov/pubme $\mathrm{d} / 22658477$ 